\title{
A Critical Review of Social Resilience Properties and Pathways in Disaster Management
}

\author{
A. M. Aslam Saja ${ }^{1}$ Melissa Teo $^{2} \cdot$ Ashantha Goonetilleke $^{2} \cdot$ Abdul M. Ziyath $^{3}$
}

Accepted: 1 October 2021 / Published online: 9 November 2021

(C) The Author(s) 2021

\begin{abstract}
Resilience as a concept is multi-faceted with complex dimensions. In a disaster context, there is lack of consistency in conceptualizing social resilience. This results in ambiguity of its definition, properties, and pathways for assessment. A number of key research gaps exist for critically reviewing social resilience conceptualization, projecting resilience properties in a disaster-development continuum, and delineating a resilience trajectory in a multiple disaster timeline. This review addressed these research gaps by critically reviewing social resilience definitions, properties, and pathways. The review found four variations in social resilience definitions, which recognize the importance of abilities of social systems and processes in disaster phases at different levels. A review of resilience properties and pathways in the disaster resilience literature suggested new resilience properties- "risk-sensitivity" and "regenerative" in the timeline of two consecutive disasters. This review highlights a causal pathway for social resilience to better understand the resilience status in a multi-shock scenario by depicting inherent and adaptive resilience for consecutive disaster scenarios and a historical case study for a resilience trajectory in a multiple disaster timeline. The review findings will assist disaster management policymakers and practitioners to formulate appropriate resilience enhancement strategies within a holistic framework in a multi-disaster timeline.
\end{abstract}

Melissa Teo

melissa.teo@qut.edu.au

1 Faculty of Engineering, South Eastern University of Sri Lanka, Oluvil 32360, Sri Lanka

2 Science and Engineering Faculty, Queensland University of Technology (QUT), Brisbane, Queensland 4001, Australia

3 Zedz Consultants Pty Ltd, Hillcrest, QLD 4118, Australia
Keywords Community resilience $\cdot$ Disaster resilience $\cdot$ Resilience assessment $\cdot$ Resilience measurement $\cdot$ Resilience properties

\section{Introduction}

As a result of the large number of devastating disaster events across the world in the last two decades (Cox and Hamlen 2015), global interest and emphasis on the resilience capabilities of communities to disasters have increased (Aldunce et al. 2015). Rapid urbanization globally, and poor development planning have increased the exposure of communities to hazards, thus generating new or exacerbating existing risks and contributing to sharp increases in disaster related losses (UNISDR 2015b). A key reason that existing hazards often evolve into disasters is the failure of communities to manage emerging risks (Birnbaum et al. 2016). Communities need to proactively mitigate risks and build resilience to reduce damages caused by disasters and to recover rapidly from disasters. However, the speed and extent of recovery from disasters often differ across communities (Burton 2015), depending on a number of complex factors such as their socioeconomic status, extent of external support received and aid provision, and their past experience of disasters. Hence, the complex resilience phenomenon requires policymakers and researchers to understand the unique characteristics of resilient communities so as to help communities to better prepare for and recover from disasters.

The etymological journey of resilience by Alexander (2013) traced the definitions of resilience in history, which highlighted that the core meaning of the term "resilience" in the past was the ability of an object or entity to return 
back to its original shape after a disturbance. The resilience concept is not new, and has been applied across many diverse disciplines, including ecology, biology, socialecological systems, social science, and psychology, over the past decades (Norris et al. 2008; Ainuddin and Routray 2012; Quinlan et al. 2015; McMillen et al. 2016). For example, the "bounce-back" analogy from engineering resilience, "resistance" concept in social vulnerability, and the "robustness" concept in social-ecological systems theory have contributed to diverse interpretations of resilience in research literature (Matyas and Pelling 2015).

New thinking in resilience recognizes the complex relationships between the built, natural, and social environments and their influences on the understanding of resilience of communities to disasters (Norris et al. 2008). Quinlan et al. (2015, p. 679) looks at this diverse approach positively, highlighting that "while multiple conceptions of resilience can be problematic in terms of common indicators and comparable metrics, they can also extend the concept to a broader spectrum of contexts and drive exploration for better approaches to implementation." This argument has gained wide attention among disaster management stakeholders since the adoption of the Sendai Framework for Disaster Risk Reduction 2015-2030 in 2015.

While resilience theory has been studied in ecology since the 1970s, social resilience, which is a critical dimension of resilience, is still not well defined and poorly understood compared to the ecological sciences (Cuthill et al. 2008; Henly-Shepard et al. 2015). Further, to advance the conceptual understanding and practical application, clarification in the use of resilience and consistency in approach are required (Zhou et al. 2010). In most of the urban resilience studies, there is less focus on social and economic resilience assessment compared to infrastructure, environment, and institutional resilience (Sharifi 2020). However, as recent studies have increasingly focused on social resilience, this article aims to critically review existent literature on social resilience definitions, properties, and pathways to advance the concept of social resilience in the context of natural hazards and disasters. Community resilience properties and pathways are commonly discussed with the focus on a single disaster, while in reality these should be investigated between two consecutive disaster events (past and future). A critical analysis of existing social resilience properties and resilience pathways between two disaster events is also presented in this article, which will contribute to integrating past learnings and future planning in building social resilience to disasters.

\section{Social Resilience Definitions in a Disaster Context}

In this section, a brief overview of the terms used in resilience literature is presented (Sect. 2.1). Subsequently, a number of social resilience definitions in the existent literature were identified using a systematic review method (Sect. 2.2) and a critical analysis of the identified social resilience definitions is undertaken (Sect. 2.3). Finally, the social resilience definition is depicted from a system thinking perspective to help operationalizing the social resilience concepts within a holistic framework in disaster management (Sect. 2.4).

\subsection{Brief Overview of Terms Used in Resilience Literature}

Resilience, community resilience, disaster resilience, urban resilience, and community resilience to disasters are defined in different ways, resulting in confusion. A comprehensive review of community resilience definitions in disaster management have been undertaken by a number of researchers (see Norris et al. (2008), Zhou et al. (2010), Manyena (2006), Mayunga (2007), and Chandra et al. (2010) for compilation of different definitions of resilience used in academic literature). Timmerman (1981, p. 21) defined resilience as "the measure of a system's or part of a system's capacity to absorb and recover from the occurrence of a hazardous event." This definition is considered one of the earliest definitions in a disaster context (Klein et al. 2003). "Despite more than three decades' worth of collective research experience on the concept, resilience still means different things to people in different fields" (Zhou et al. 2010, p. 22). However, this diversity in definition yields significant collective learnings and experiences that can be applied in a disaster context (Zhou et al. 2010).

Resilience can be understood as "an attribute (e.g., ability or capacity), a process, and/or an outcome associated with successful adaptation to, and recovery from, adversity" (Pfefferbaum et al. 2013, p. 251). For example, UNISDR (2009, p. 22) defined disaster resilience of communities as "the ability of a community exposed to hazards to resist, absorb, accommodate to and recover from the effects of a hazard in a timely and efficient manner, including through the preservation and restoration of its essential basic structures and functions." The resilience of a community to a disaster is determined not only by the ability to recover after a disaster, but also the degree to which a community has the necessary resources and capability to organize itself, both prior to and after a disaster (UNISDR 2015a). Resilience can also be defined at 
individual, community, organization, or systems levels depending on the research focus (Boon et al. 2012). For example, Norris et al. (2008) categorized resilience definitions at varying levels such as physical, ecological, social, city, community, and individual. In contrast, Chandra et al. (2010) analyzed how each definition fits within different phases of a disaster management cycle.

Definition of community resilience to disasters continues to evolve based on the research context, lessons learned, and past experiences in managing disasters. Definitions for community resilience from the literature that capture the words "disaster" OR "hazard" AND "resilience" were extracted. Keywords in each definition were analyzed for their coverage in different phases of the disaster management cycle (ex-ante, during a disaster period, and ex-post phases). Analysis of these key terms demonstrated that resilience is most commonly referred to as the ability or capacity of a community to recover back after a disaster (Mayunga 2007). However, new definitions increasingly frame community resilience to disasters as encompassing all phases of a disaster and not just limited to disaster response and recovery phases (Mayunga 2007).

The term "community resilience" is mostly used as a concept of overall resilience that includes all key dimensions such as social, economic, institutional, environmental, and physical. In social resilience, the focus has commonly been either on the resilience of social entities or on social mechanisms or both. Similarly, economic resilience definitions focus on different levels of economic systems such as micro-, meso-, and macro-economic (Rose and Krausmann 2013). The key difference in the definitions of different thematic concepts such as social resilience and economic resilience is the difference in the system in focus, whether social or economic. However, the terms, "community resilience" and "social resilience" are sometimes interchangeably used in the literature.

Similar to the confusion and inconsistencies in defining resilience by researchers, practitioners, and policymakers (Bahadur, Tanner et al. 2015), there is also a lack of consistency in social resilience definitions. Social resilience in a disaster context may involve a transformation of social systems to another state, rather than conservation of functionalities of the social system (Alexander 2013), that is, conservation means return to pre-disaster state and transformation means the system does not necessarily need to return to its pre-disaster state, but it transforms to a new state. Social resilience to disasters is determined by the ability to recover after a disaster that is measured by the degree to which a community has the necessary resources and capability to organize itself, both prior to and after a disaster (UNISDR 2015a). Social resilience needs to be conceptualized as the proactive ability of social entities and mechanisms as opposed to defining it only as the reactive capability for responding to a crisis (Matyas and Pelling 2015 ) and with the adaptation and bouncing forward phenomena (Alexander 2013; Manyena 2016).

The work by Adger (2000) on ecosystems is widely acknowledged as the first study to define social resilience (Keck and Sakdapolrak 2013). In the context of socioecological systems, in this case a mangrove conversion, Adger (2000, p. 361) defined social resilience as "the ability of communities to withstand external shocks to their social infrastructure." Adger (2000) further highlighted the need to consider the contextual social attributes in defining social resilience because of varying differences in community institutions and resource priorities. Additionally, the diversity and dynamics of the context, in which the concept of resilience is operationalized, introduce further complexity to the definition (Alexander 2013).

\subsection{Identification of Social Resilience Definitions from the Literature (PRISMA Method)}

The Preferred Reporting Items for Systematic Reviews and Meta-Analyses (PRISMA) method was used to select social resilience studies for a detailed review. PRISMA is an established method for guiding systematic review of academic literature, and is based on four steps as detailed in Fig. 1: Identification, Screening, Eligibility, and Inclusion. At the identification stage of the PRISMA method, articles were searched using a search string "(Social) OR (Community) AND (Resilience)" in Title, Abstract, and Keywords of articles published during 2005-2016 in the Scopus database. This search resulted in 12,121 articles, which were further reduced to 6,811 articles in stage 2 : screening, using further limiters such as "relevant subject areas and English language." In stage 3: Eligibility, 1,194 articles were obtained for further screening by excluding articles irrelevant to disaster studies. Another exclusion criterion based on the title and abstract review resulted in 172 articles for full-text review. In stage 4: Inclusion, the PRISMA method identified 10 different contextual social resilience definitions from 31 social resilience studies derived by screening the full text of the 172 eligible manuscripts and six articles from the references of the 31 articles for further analysis. Table 1 shows the 10 selected social resilience definitions.

\subsection{Analysis of Social Resilience Definitions}

Social resilience definitions can be classified into the following four sub-categories for ease of analysis: (1) social entities or largely social systems that include families and ranging to wider community such as social groups, organizations, resources, and structures; (2) social mechanisms such as understanding and managing emerging risks as well 
Fig. 1 Preferred reporting items for systematic reviews and meta-analyses (PRISMA) flowchart for the identification of journal articles on social resilience definitions

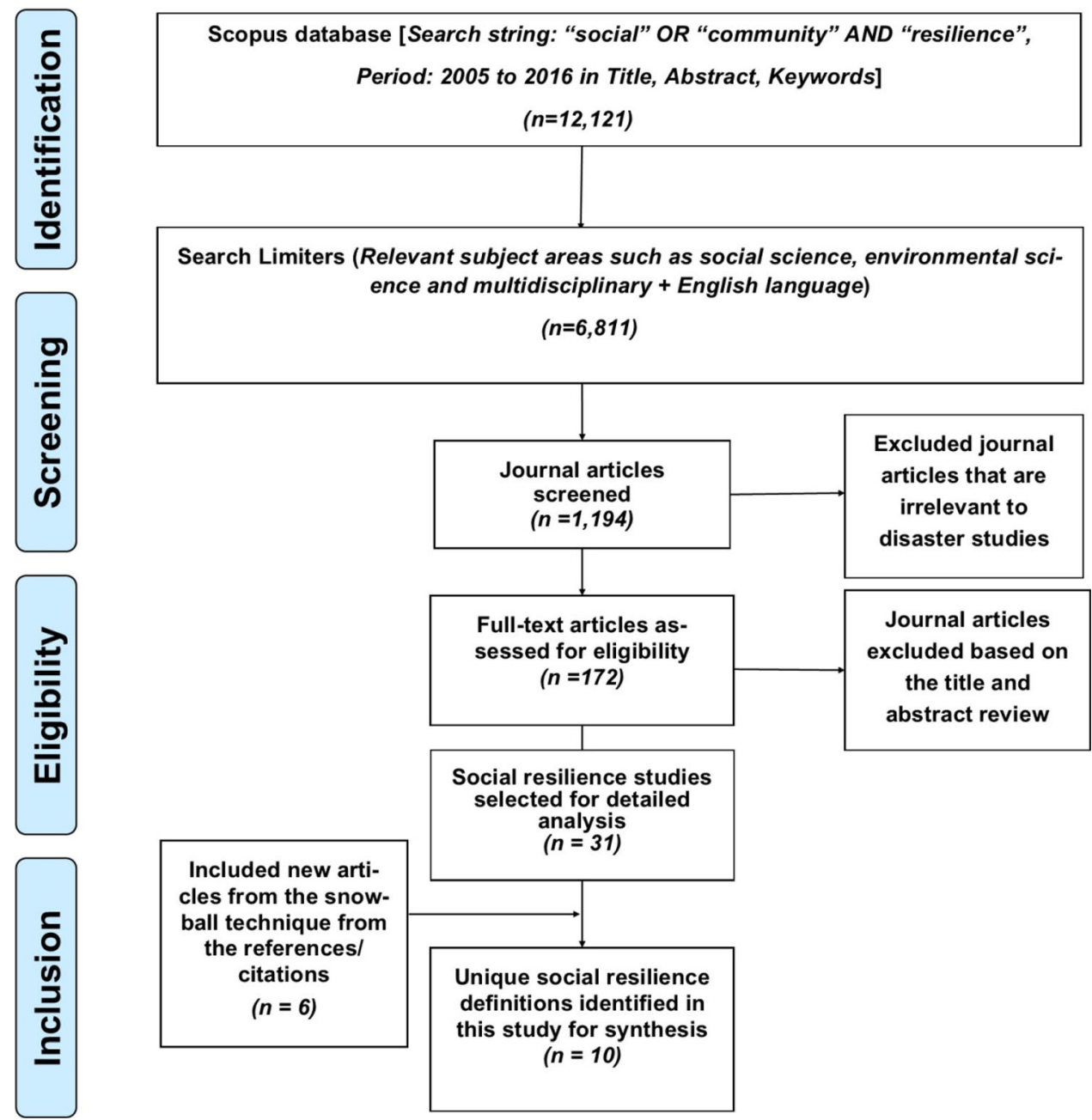

as self-organization and transformation capacities; (3) social entities and mechanisms (both outcome and process oriented features); and (4) coping, adaptive, and transformative (CAT) capacities. As in Table 1, the 10 social resilience definitions were categorized into the first three sub-categories.

(1) Social resilience as an ability of social entities to cope with, withstand, and/or recover from disasters: Social resilience is defined by some researchers as the ability or capacity of people, social units, and social systems to cope with, withstand, and/or recover from disasters as shown in Table 1. Social entities in this definition include individuals, families/households, communities, organizations, and specific social groups. For example, in the context of seismic hazards, Bruneau et al. (2003) defined social resilience as the ability of social units to contain, recover from, and mitigate future effects of earthquakes. This definition covers both the pre- and post-event phases of the disaster management cycle such as preparedness and recovery. Similarly, Lorenz (2013) used social systems in their definition, while Maguire and Hagan (2007) used social groups. Further, the social resilience definition proposed by Khalili et al. (2015) focuses on the ability of a community to withstand external social shocks towards enhancing social capacity. However, the definitions focused on assessing the abilities of social entities have limited focus on assessing the abilities of social mechanisms, which is also important for comprehensive definition of social resilience.

(2) Social resilience as an ability of social mechanisms to cope with, withstand, and/or recover from disasters: An alternate way for understanding social resilience is to conceptualize it as a social mechanism. Social mechanism includes community processes such as decision making, use of resources/features, and community actions. These are important in the process of building a disaster resilient community. However, only a few researchers have considered social resilience as the ability of social mechanisms to cope with external shocks or as a process or as a 
Table 1 Selected social resilience definitions from the literature

\begin{tabular}{|c|c|c|c|}
\hline Type of definitions & Definition context & Social resilience definition & References \\
\hline \multirow[t]{6}{*}{$\begin{array}{l}\text { Ability of social } \\
\text { entities }\end{array}$} & $\begin{array}{l}\text { Disasters (common } \\
\text { definition to all } \\
\text { disasters) }\end{array}$ & $\begin{array}{l}\text { "The capacity of social groups and communities to recover from, or } \\
\text { respond positively to, crises"; "The capacity of a social entity (e.g., a } \\
\text { group or community) to bounce back or respond positively to } \\
\text { adversity" }\end{array}$ & $\begin{array}{l}\text { (Maguire and } \\
\text { Hagan } 2007 \\
\text { p. } 17 \text { ) }\end{array}$ \\
\hline & $\begin{array}{l}\text { Community seismic } \\
\text { resilience }\end{array}$ & $\begin{array}{l}\text { "Ability of social units (e.g., organizations, communities) to mitigate } \\
\text { hazards, contain the effects of disasters when they occur, and carry out } \\
\text { recovery activities in ways that minimize social disruption and mitigate } \\
\text { the effects of future earthquakes" }\end{array}$ & $\begin{array}{l}\text { (Bruneau et al. } \\
\text { 2003, p. 4) }\end{array}$ \\
\hline & $\begin{array}{l}\text { Disasters (common } \\
\text { definition to all } \\
\text { disasters) }\end{array}$ & $\begin{array}{l}\text { "Internal ability of the social system to counteract events described as the } \\
\text { failure of expectation toward its environment during disasters, crises } \\
\text { and emergencies" }\end{array}$ & $\begin{array}{l}\text { (Lorenz 2013, } \\
\text { p. 12) }\end{array}$ \\
\hline & $\begin{array}{l}\text { Disasters (common } \\
\text { definition to all } \\
\text { disasters) }\end{array}$ & $\begin{array}{l}\text { "The ability of a community to withstand external social shock toward } \\
\text { enhancing social capacity to resist disaster losses during disaster and } \\
\text { regenerate after disaster" }\end{array}$ & $\begin{array}{l}\text { (Khalili et al. } \\
\text { 2015, p. 249) }\end{array}$ \\
\hline & $\begin{array}{l}\text { Socio-ecological } \\
\text { systems }\end{array}$ & $\begin{array}{l}\text { "Ability of groups or communities to cope with external stresses and } \\
\text { disturbances as a result of social, political and environmental change" }\end{array}$ & $\begin{array}{l}\text { (Adger } 2000 \text {, } \\
\text { p. } 347 \text { ) }\end{array}$ \\
\hline & $\begin{array}{l}\text { Disasters (common } \\
\text { definition to all } \\
\text { disasters) }\end{array}$ & $\begin{array}{l}\text { "The capacity of a social system (e.g., an organization, city, or society) to } \\
\text { proactively adapt to and recover from disturbances that are perceived } \\
\text { within the system to fall outside the range of normal and expected } \\
\text { disturbances" }\end{array}$ & $\begin{array}{l}\text { (Boin et al. 2010, } \\
\text { p. 9) }\end{array}$ \\
\hline \multirow[t]{3}{*}{$\begin{array}{l}\text { Ability of social } \\
\text { mechanisms }\end{array}$} & Drought mitigation & $\begin{array}{l}\text { "Social coping mechanisms that are used to cope with extreme } \\
\text { unmanageable shocks" }\end{array}$ & $\begin{array}{l}\text { (Rockström } \\
\text { 2003, p. 871) }\end{array}$ \\
\hline & Coastal flooding & $\begin{array}{l}\text { "Social resilience }=\text { risk perception } \times \text { self-perception } \times \text { accepting change } \\
\times \text { self-organization" }\end{array}$ & $\begin{array}{l}\text { (Shaw et al. } \\
\text { 2014, p. 202) }\end{array}$ \\
\hline & $\begin{array}{l}\text { Disasters (common } \\
\text { definition to all } \\
\text { disasters) }\end{array}$ & $\begin{array}{l}\text { "Individuals' sense of the ability of their own community to deal } \\
\text { successfully with the emerging threat" }\end{array}$ & $\begin{array}{l}\text { (Kimhi and } \\
\text { Shamai } 2004, \\
\text { p. } 442)\end{array}$ \\
\hline $\begin{array}{l}\text { Ability of social } \\
\text { entities and } \\
\text { mechanisms }\end{array}$ & $\begin{array}{l}\text { Disasters (common } \\
\text { definition to all } \\
\text { disasters) }\end{array}$ & $\begin{array}{l}\text { "The ability of a community's social environment to effectively } \\
\text { anticipate, cope with, and recover from disasters, which depends on the } \\
\text { presence and robustness of other community features, resources, and } \\
\text { processes" }\end{array}$ & $\begin{array}{l}\text { (Kwok et al. } \\
\text { 2016, p. 205) }\end{array}$ \\
\hline
\end{tabular}

combination of risk perception, ability of self-organization, and transformation. Since there are multiple social entities as defined in category (1) above, social resilience definitions that have focused on social mechanisms have failed to specify the resilience of multiple social entities. This has limited the application of the definition in a practical and inclusive way when social resilience is measured.

(3) Social resilience as an ability of both social entities and mechanisms to cope with, withstand, and/or recover from disasters: In a disaster context, Kwok et al. (2016) considered social resilience as the ability and robustness of community structures, resources, and processes to anticipate, cope with, and recover from disasters. Social resilience definitions in this context have focused on social entities and mechanisms as opposed to considering only the community as a resilience entity. Defining social resilience in terms of the ability of social entities and mechanisms helps to conceptualize social resilience not only as resilience entities, but also with resilience mechanisms and their interconnections with resilience entities. However, capturing the accurate inter-relationship between entities can still be a challenge, although a system approach can help to capture the dynamic nature of social resilience characteristics.

(4) Social resilience as coping, adaptive, and transformative (CAT) capacities: Social resilience is also defined in terms of a community's coping, adaptive, and transformative capacities. Keck and Sakdapolrak (2013) highlighted in their multidisciplinary review of social resilience concepts and definitions that the focus has been on the capacity of social actors when social resilience is conceptualized as CAT capacities. It is also helpful to define social resilience using CAT capacities, because they can capture dynamic attributes of social systems at multiple scales with the combination of different capacities and the interaction 
between capacities to ensure the stability of a system. For example, coping is the ideal strategy to manage disaster risk. However, when the coping capacity is exceeded, the adaptive capacity will be activated (Serfilippi and Ramnath 2018). When adaptation is not adequate to overcome the disaster risk, the system will progress towards transformation to sustain system stability (Serfilippi and Ramnath 2018). This process can help social systems to achieve the desired resilient status through CAT capacities.

In the natural resource management context, Cuthill et al. (2008) and Maclean et al. (2014) defined social resilience as adaptation and transformation strategies of individuals and communities to counter social, environmental, economic, and political challenges. To define social resilience, Maclean et al. (2014) have drawn the concept of adaptation and transformation strategies from social-ecological system perspectives and health and social sciences disciplines. They inter-related social resilience to the adaptive capacity of people individually and collectively. These definitions do not explicitly imply the ability of all social entities, and it is mostly aligned to the ability of social mechanisms. Since the capacity-based resilience definitions are widely used across different disciplines, each of the capacity components is discussed in detail to understand differences in its conceptualization compared to categories (1), (2), and (3) above. Table 2 summarizes each of the capacities, which are further explained below.

Coping capacity: Coping capacity is the anticipative, absorptive, and recovery capacity to a disaster (Parsons et al. 2016). An example of coping capacity is the level of resources and the manner in which individuals or families use these resources to face the adverse consequences of a disaster. Keck and Sakdapolrak (2013) viewed it as a reactive absorptive capacity for coping after a disaster to restore the functioning of the community to its previous level in the short term. On the other hand, it can be defined as "means by which people or organizations use available resources, skills, and opportunities to face adverse consequences that could lead to a disaster" (Parsons et al. 2016, p. 1), which can be viewed as a proactive capacity to an emerging disaster. While both definitions consider the same resilience capacity to a disaster, two different interpretations can be identified based on the time and purpose of use. The proactive interpretation aims to use the coping capacities to face a disaster, while reactive interpretation aims to restore the functioning of the community after a disaster.

Adaptive capacity: Adaptive capacity is defined as the ability to mobilize actions, processes, and decisions that enable reflections and adjustments in existing social norms and processes through learning (Nelson et al. 2007; Parsons et al. 2016). For example, considering a community that is vulnerable to flooding, adaptive capacity may involve preventive or mitigation strategies based on the learnings from past flooding experience. Hence, possible adaptive strategies could include relocating people living in high flood risk areas, or constructing levees in flood risk areas. Keck and Sakdapolrak (2013) defined this as an ex-ante preventive capacity that helps the community to anticipate future risk through lessons learned from past disasters. How adaptive capacity is linked to social resilience is a contested discussion in academic literature, since it is attributed in many different ways such as robustness of the system, level of resilience, an element of resilience, or one of the factors influenced by resilience (Klein et al. 2003; Lorenz 2013).

Transformative capacity or participative capacity: In the realization process of a resilient system, transformation and transition are key components (Xue et al. 2018). Transformative capacity is defined as the measure of capacity to self-organize and ability of the system to change its own structures (Lorenz 2013). Transition is the ability to successfully move into a new phase or sustain in a new timeframe while adapting to disturbances from transformation. For example, the key factors of transformative capacity include policy direction, strategic thinking, leadership role, and innovation (Bahadur, Peters et al. 2015). Besides, it is an ex-ante participative capacity to make future development decisions by understanding future disaster risks (Keck and Sakdapolrak 2013). The transformative capacity at smaller scale could develop social resilience at a larger scale, providing new opportunities and

Table 2 Social resilience components as coping, adaptive, and transformative (CAT) capacities

\begin{tabular}{|c|c|c|}
\hline CAT capacities & When/phase of a disaster & Types of capacities \\
\hline Coping capacity & Ex-post (evacuation, relief, recovery) & Anticipative, absorptive, and recovery capacity \\
\hline Adaptive capacity & Ex-ante (prevention and mitigation) & $\begin{array}{l}\text { Mobilizing resources, decision making, leaning, and } \\
\text { adjustments }\end{array}$ \\
\hline $\begin{array}{l}\text { Transformative } \\
\text { capacity }\end{array}$ & $\begin{array}{l}\text { Ex-ante (integrative preparedness phase of reconstruction/ } \\
\text { development) }\end{array}$ & $\begin{array}{l}\text { Self-organize, policy participative, innovation, and } \\
\text { leadership }\end{array}$ \\
\hline
\end{tabular}


room for innovation to build greater resilience to future disasters (Folke et al. 2010). Transformative capacity is important in addition to coping and adaptive capacities (Keck and Sakdapolrak 2013; Lorenz 2013; Manyena 2016), since the importance of self-organization and participation in decision-making processes have also been highlighted as important factors during disaster response.

Many different interpretations of CAT capacities result in numerous social resilience definitions. For example, a review of adaptive capacity concepts highlighted that transformation is one of the properties of adaptive capacity and it is mostly attributed to governance and institutions (Engle 2011). Further, adaptive and transformation capacities are viewed as proactive capacity to prepare for emerging future disasters and these are based on lessons learned from past disasters. This suggests that transformative or participative capacity needs to be considered in all phases of a disaster, rather than only emphasising it in either pre- or post-disaster phase. Masnavi et al. (2018) in their review identified three conceptual approaches to resilience thinking: resilience as recovery, as an adaption capacity, or as a change, which is similar to defining resilience in one of the CAT capacities. However, a key challenge in defining social resilience using CAT capacities is the difficulty to delineate those capacities in a specific timeline or disaster phases. This is because, at a given point in time, the status of a community is always between a recent past disaster and a future disaster, and hence CAT capacities can eventuate simultaneously (Béné et al. 2015). Moreover, CAT capacities vary mostly based on the time extent of different disaster phases and the complexity of the disaster situation.

\subsection{Social Resilience Definition from a Systems Thinking Approach}

Based on different definitions of social resilience to disasters, a conceptual map of key system components of social resilience was created as shown in Fig. 2. A system perspective is considered for social resilience to disasters as an overlapping system of multiple resilience characteristics belonging to social resilience entities and processes at multiple levels. Social entities are complex adaptive systems (CAS), experiencing dynamics and stresses internally and externally and disaster-affected social entities should be recognized as CAS systems, for greater understanding (Day 2015). Accordingly, conceptualizing social resilience includes the mapping of abilities of social entities and mechanisms and their interrelationships, and understanding them at different scales such as individual, family, community, and social groups/organizations. As shown in Fig. 2, the abilities of both social entities and social mechanisms are considered along the different phases of a disaster, that is, ex-ante, disturbance, and ex-post. A " $5 \mathrm{~S}$ " social resilience model developed by Saja et al. (2018) is an example to consider for such a system-based approach for assessing social resilience in a disaster context. However, future research in conceptualizing and defining social resilience need to be aligned to overcome the challenges of a dynamic and complex nature of social resilience phenomena (Saja et al. 2021).

Boon et al. (2016) argued that the strategies for resilience building programs should be integrated across multiple entities from micro to macro levels and linking elements from complex and diverse systems at several levels. Since there is a growing need for understanding social resilience at various social levels (Kulig and Botey 2016), innovative approaches are needed to assess the dynamic interactions within and between multiple social resilience dimensions (Buckle 2006). Since resilience is presented as the concept of managing responses to the disturbances caused to the systems, similar to sustainability that explains the long-term persistence of systems, both resilience and sustainability concepts need to be collectively addressed (Chambers et al. 2019). Hence, the linkages between resilience and sustainability need to be wellestablished based on the complementarity between the two concepts that will help to define and operationalize a holistic approach to sustainable development and disasterrisk management.

\section{Social Resilience Properties and Pathways in Disaster Phases}

Social resilience is viewed as a time-based sequential phenomenon because its properties are event dependent and time-sensitive (Constas et al. 2014). As a result, the changes in the resilience status can be measured before and after an event or over a period of time. In Sect. 2, various resilience definitions were discussed based on four categories of conceptualizations. However, when the definition of resilience is discussed, three key elements between numerous concepts of resilience need to be delineated: severity of the disaster, the speed of recovery, and the final status of recovery (Boin et al. 2010). Further, recent discussions have argued for a more proactive stance for resilience to include disaster risk reduction, since the traditional practice is more towards a reactive approach (response preparedness) that embraces the engineering version of resilience (De Bruijne et al. 2010). Hence, the three key elements delineating disaster resilience concepts highlighted above and the recent trends in proactive framing of disaster management, necessitates a detailed discussion on the properties and pathways of resilience, which is one of the key objectives of this article. This 
Fig. 2 Systems thinking to define social resilience as abilities of social entities and mechanisms

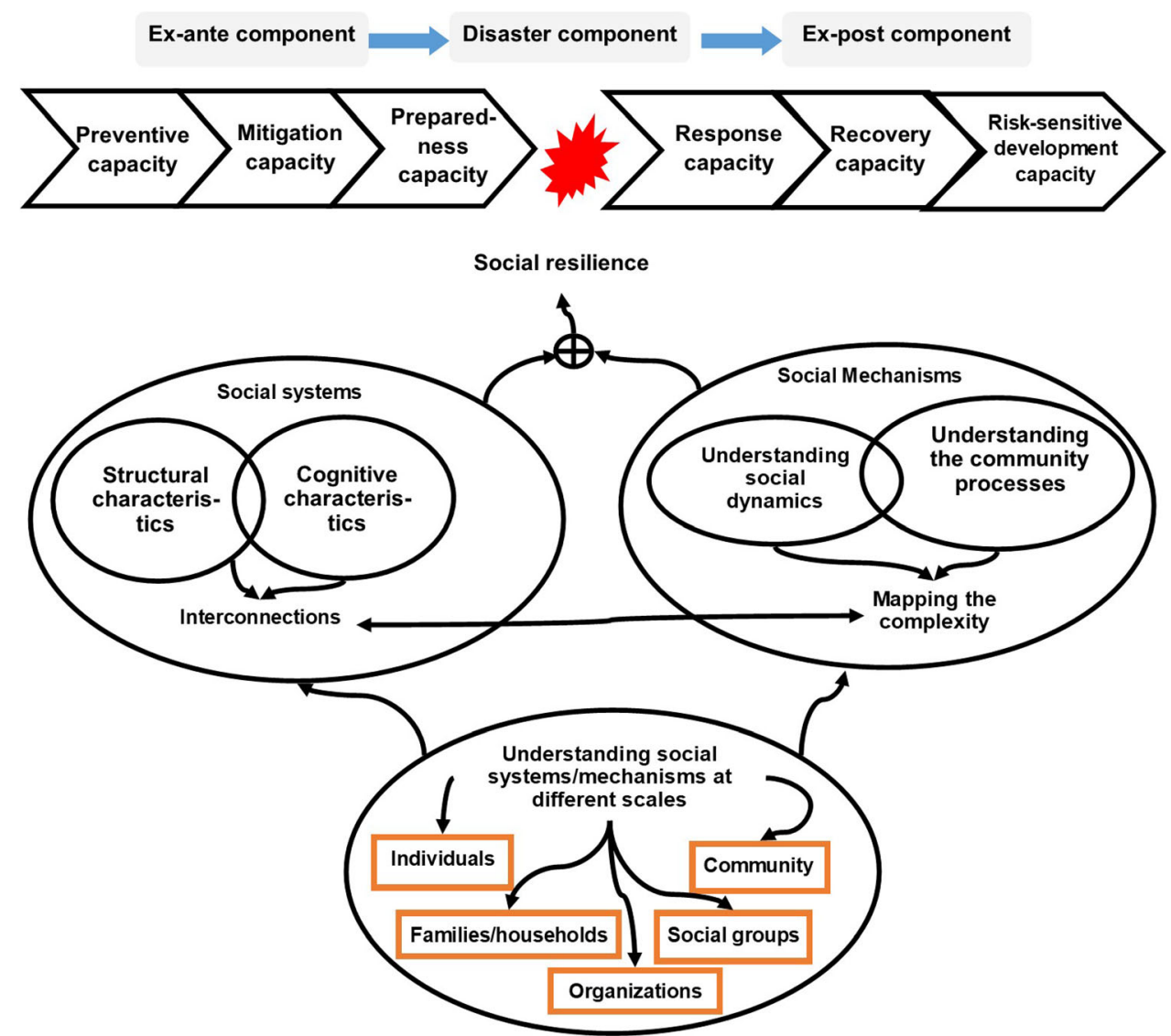

discussion will help to comprehensively understand social resilience in a future disaster context.

\subsection{Social Resilience Properties}

Bruneau et al. (2003) described four properties of resilience, known as "4R": robustness, redundancy, resourcefulness, and rapidity. Kimhi and Shamai (2004) outlined similar properties as Bruneau et al. (2003), though using different terms, for example "redundancy" as "resistance," "rapidity" as "recovery," and "resourcefulness" as "creativity" (Table 3). However, "risk-sensitivity" and "regenerative" as key resilience properties in the pre- and post-disaster phases need to be included as resilience properties in addition to the existing " $4 \mathrm{R}$ " properties (ESCAP 2015). "Risk-sensitivity" and "regeneration" in principle are about resilient design and planning in the predisaster risk reduction and post-disaster reconstruction activities, respectively. Post-disaster reconstruction provides a window of opportunity to not only return to the predisaster level, but also to enhance resilience and to regenerate social and ecological systems (Oliver et al. 2013), thus is an important property of resilience. "Risksensitivity" is similar to "regenerative," but is considered when a new system is built in a pre-disaster context. The targets set out in the Sendai Framework for Disaster Risk Reduction 2015-2030 are also primarily aligned with resilient, sustainable, and regenerative communities in a way that is sensitive to disaster risks and its drivers (UNDRR 2019).

Figure 3 shows the " $6 \mathrm{R}$ " resilience properties as a function of resilience status and time (adapted from Maguire and Hagan (2007) and "4R" properties of Bruneau et al. (2003)), between two disaster events. The aim of this study was to understand the resilience properties and pathways of a community between two disaster events (in a real time scenario), which has not been investigated in detail in the literature. In a disaster context, resilience is mostly viewed as desirable characteristics of social systems and processes (Boin et al. 2010), which can be delineated in pre- and post-disaster phases. Hence, resilience properties of a social system need to be described, since benchmarking a resilient social system is a complex process. For example, inherent capacity that exists before a disaster becomes a coping and adaptive capacity in response to the disaster. In social resilience context, these are further amplified to transformation capacities. 
Table 3 "6R" resilience properties and their descriptions. Source Adapted from Adger (2000), Bruneau et al. (2003), Maguire and Hagan (2007), Oliveret al. (2013), and ESCAP (2015)

\begin{tabular}{|c|c|}
\hline $\begin{array}{l}\text { Resilience } \\
\text { properties }\end{array}$ & Description \\
\hline Robustness & Ability of the social systems and processes to withstand a given level of stress without further loss and damage \\
\hline Redundancy & $\begin{array}{l}\text { Degree of disturbances that can be accommodated (a maximum threshold that is capable of satisfying functionality), also } \\
\text { termed as "resistance" (Maguire and Hagan 2007) }\end{array}$ \\
\hline Resourcefulness & $\begin{array}{l}\text { Ability of learning and achieving higher level of functionality to prioritize problems and achieve goals, also termed as } \\
\text { creativity (Maguire and Hagan 2007) }\end{array}$ \\
\hline Rapidity & $\begin{array}{l}\text { Capacity to recover back to the previous state to contain losses and avoid future disruption, also known as recovery (Maguire } \\
\text { and Hagan 2007) }\end{array}$ \\
\hline Risk-sensitivity & Ability to protect development and transformation gains made over time from disaster impact (ESCAP 2015) \\
\hline Regenerative & $\begin{array}{l}\text { Capacity to restore social and interconnected systems that give new life, and create social and natural capital that are more } \\
\text { viable in addition to maintaining the balance between those systems, which is sustainable (Oliver et al. 2013) }\end{array}$ \\
\hline
\end{tabular}

Fig. 3 "6R" resilience properties in the timeline of two subsequent disaster events Source Adapted from Bruneau et al. (2003) and Maguire and Hagan (2007).

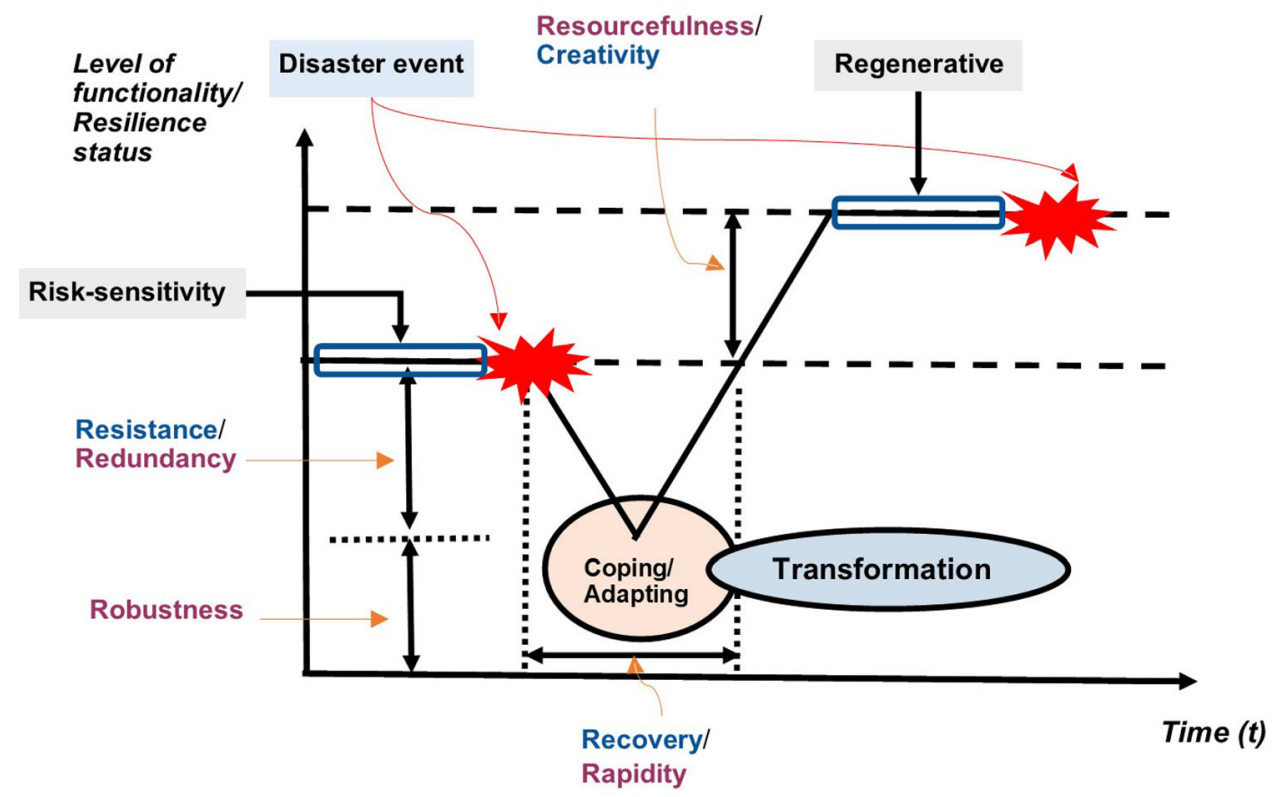

\subsection{Social Resilience Pathways}

Typically, every community responds to a disaster event differently, due to their unique set of capacities in dealing with such adversities (Sherrieb et al. 2010). Similarly, a community's reaction has been found to vary with every subsequent disaster event encountered (Maguire and Hagan 2007), largely as a result of past disaster experiences and changes in socioeconomic conditions. Therefore, understanding the past social resilience pathways ${ }^{1}$ that facilitate disaster preparedness, response, and recovery, will assist governments, disaster practitioners, and communities to

\footnotetext{
${ }^{1}$ Pathway is described in this article as the changes in the level of social resilience along the development timeline and between consequent disaster events.
}

devise strategies to build more resilient communities. Currently, mapping of trajectories depicting social resilience pathways in a disaster context has mainly focused on a single disaster event, which has either already occurred or yet to occur. However, it is important to understand the social resilience pathway of a community between two consecutive disaster events for a given community that has already faced at least one disaster in the past and is in a predisaster stage for the next emerging/potential disaster at a point in time. Such an understanding will assist in formulating strategies for enhancing appropriate inherent and adaptive resilience strategies based on past experiences and existing status.

Frankenberger et al. (2012) demonstrated trajectories of social resilience to food scarcity as successive shocks with multiple alternative community recovery scenarios. Similar 
trajectories of social resilience causal pathway along the phases of two consecutive disasters are shown in Fig. 4, based on disaster management and resilience concepts of Cutter (2016), Mayunga (2007), Constas et al. (2014), and Frankenberger et al. (2012). The limitation in depicting social resilience pathways between two major disasters is the small-scale disturbances along the timeline. It is assumed that the severity scale of disaster \#1 and disaster \#2 are large with significant impact on the resilience status of communities. Figure 4 is a forward-looking resilience status in real time, where the community is in a post-disaster \#1 and pre-disaster \#2 state along with its potential future resilience state after the occurrence of next disaster (that is, disaster \#2, which is the future predicted disaster).

As shown in Fig. 4, social resilience can be categorized as being inherent and adaptive resilience (Cutter 2016). In terms of resilience properties discussed in Fig. 3, inherent resilience is about resistance/redundancy and robustness, whereas the adaptive resilience is resourcefulness/creativity. While inherent resilience is the ex-ante resilience, which is a baseline for benchmarking existing conditions, adaptive resilience is the ability to respond to changes due to a disaster event and its ex-post (post-disaster component) (Cutter 2016). When a disaster first strikes (disaster
\#1 in Fig. 4), adaptive social resilience can alter the community's inherent social resilience depending on the capacity and willingness of social entities to learn from previous disasters. An enhanced level of inherent social resilience will help the community to recover to the previous level or better than before depending on its adaptive social resilience (scenario 1 or 2). However, it is also possible that the inherent social resilience to future disasters (disaster \#2 in Fig. 4) has deteriorated due to an absence of resilience building efforts that may result in lack of adaptive social resilience.

Scenarios 3 and 4 depict low levels of social resilience that either results in the community reaching a worse state than before or being unable to recover (Fig. 4). Time difference between $t=t_{1}$ and $t=t_{3}$ largely depends on when the next disaster strikes at $t=t_{3}$. In this review, the focus is on inherent resilience at the preparedness phase for future disasters (disaster \#2), and the current status of the social entity is between $t=t_{2}$ and $t=t_{3}$, since it is assumed that the community has already faced a disaster (disaster \#1). The aim of the trajectory shown in Fig. 4 is to understand four potential scenarios to plan for the future disaster (disaster \#2). The trajectory facilitates an insight into the status of a community (in normal and disaster contexts) and

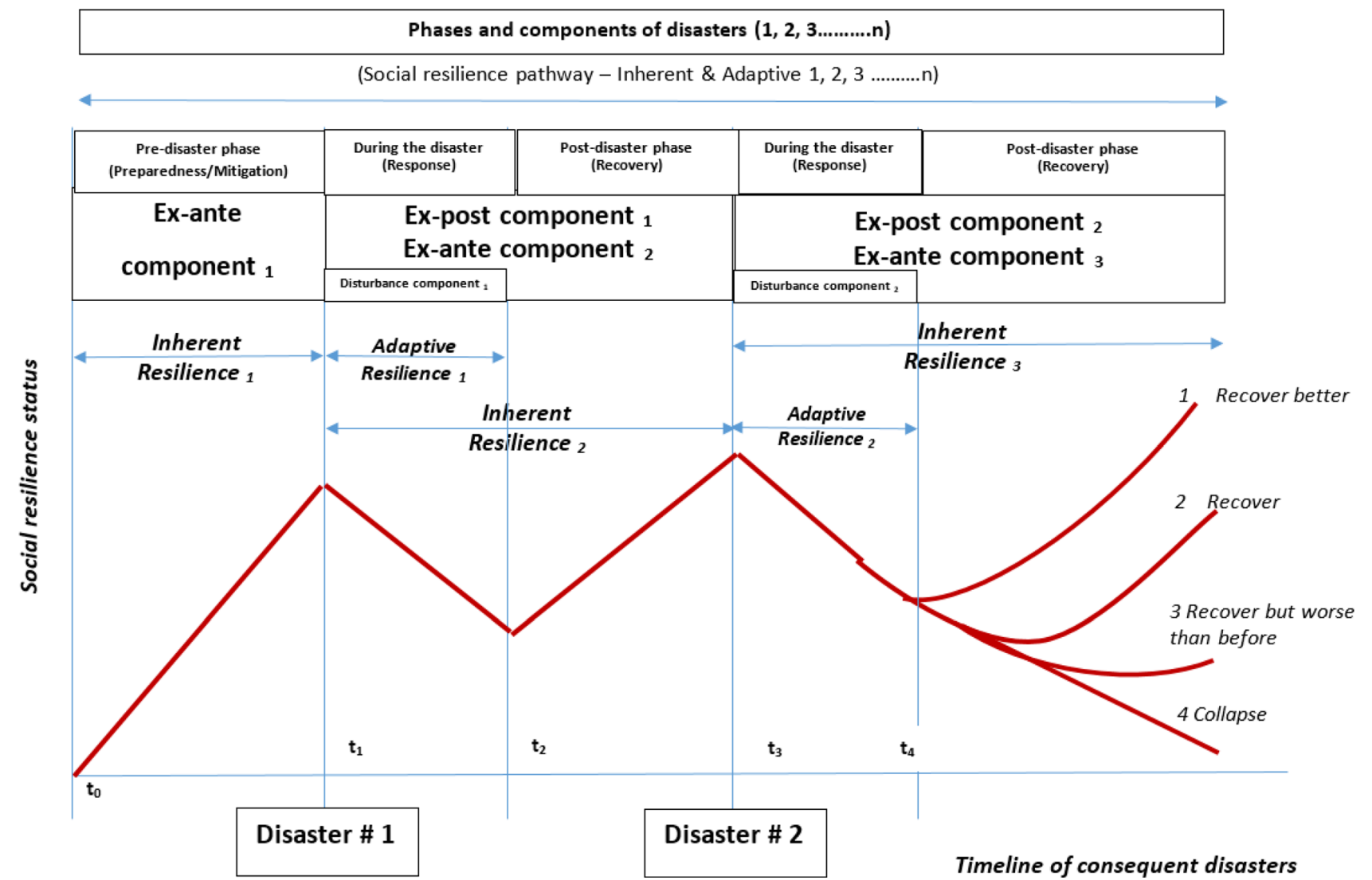

Fig. 4 Causal pathway of social resilience to two subsequent disasters Source Developed based on Frankenberger et al. (2012). 
its social resilience capabilities in real time (at the time of measurement). The disaster events \#1 and \#2 shown in Fig. 4 are considered to be disaster events with large impact, although many smaller disturbances may have occurred between two major disaster events. The impact due to these smaller disturbances was assumed negligible in this trajectory.

\section{Case Studies from Sri Lanka}

The variations in social resilience levels and pathways on the timeline with two consecutive disasters described in Fig. 4 are explained using the two examples below. The first example is about a community in Sri Lanka that experienced a 10-month long drought (disaster/disturbance \#1) before sudden arrival of heavy monsoon rain. A mini cyclone and localized heavy flooding (disaster \#2) occurred as a result of torrential rains, which left over 200,000 people stranded, 15,000 displaced, and over 5000 homes destroyed (Perera 2012). Before the impact of the monsoon rain, the long drought had destroyed $23 \%$ of their expected rice harvest, putting many farmers at risk, resulting in the lack of adaptive capacity to mitigate against the floods among the drought affected farmers. There were also increased levels of debt among the farming community due to the increase in the price of rice seeds that forced them to liquidate household assets to repay the debts, resulting in further depletion of their livelihoods (Coslet et al. 2017). In this example, disaster \#2 occurred just after 10 months from the occurrence of disaster \#1. People were not able to recover adequately from disaster \#1, or build inherent resilience for disaster \#2, due to the short time gap of 10 months between two consecutive disasters.

The second example is about the coastal communities in the southeastern part of Sri Lanka that was devastated by the 26 December 2004 tsunami. The communities also experienced a severe flood disaster event in 2011. Since the tsunami disaster was a new experience, the damage was catastrophic due to a lack of awareness and preparedness. As a result, it took many years for the affected communities to recover back to their previous status or to a better position than the position before the tsunami. Although communities were able to rebuild their inherent resilience during the period of tsunami recovery, the flood disaster in 2011 again resulted in declining levels of social resilience. This example is also similar to the first example, but there are two key differences. First, the seven-year time gap between two disaster events in the second example is significant than that of example 1, which highlights the importance of timeframe and the gap between high impact disasters in building resilience. The second difference is that people had gained a certain level of inherent resilience to face disaster \#2, although the recovery process had not reached to a level to build the communities to a better status than the status before disaster \#1.

The above two examples illustrate how the level of social resilience changes over the course of two disaster events. In both scenarios, it took more time and effort for the community to recover to a better status after disaster $\# 2$, although the severity of both disasters were lower in example 1 compared to the disaster events in example 2 . Hence, the time gap between two consecutive disaster events and severity of those disasters highly influence the changes in inherent and adaptive resilience of communities to disasters. Further, the correlation between inherent and adaptive resilience has not been empirically investigated (Cutter 2016), which is not always achievable as it may require a longitudinal study of the before, between, and after disaster phases to explore the optimal coping and recovery pathways of a community. From a research point of view, it is important to improve the understanding of social resilience pathways along the disaster timeline of a community (at minimum between two consecutive disasters). Therefore, it is critical to study the variation in social resilience pathways along the associated causes in different social contexts such as urban versus rural, coastal versus mountain communities, and exposure to different types of natural hazards.

An example of multi-shocks in Sainthamaruthu Divisional Secretariate division (DS division), which is one of the administrative divisions in the southeastern coast of Sri Lanka is provided below from the historical records, in order to understand the social resilience trajectory in different major disaster events over the past centuries.

The historical records show that a series of cyclones hit Sainthamaruthu in the nineteenth and twentieth centuries. This includes severe and medium category cyclones in 1845, 1891, 1907, 1921, and 1978. Although the data on damages and losses are not available for these cyclone events, the 1978 cyclone was reported to be the major cyclone in the historical records available, and it took three months to bring back to the normalcy. Three major floods were also reported in this area: in 1933, 1957, and 2010. The 2004 tsunami was the major devastating disaster in the history of this area, which killed 768 people (the 2004 population of Sainthamaruthu division was 25,605 people) and entirely wiped out half of the Sainthamaruthu division, leaving 722 families homeless and more than 2500 houses severely damaged. It took more than five years for recovery from the tsunami damages. (Translated and summarized from the book History of Sainthamaruthu (Jameel 2009, pp. 391-404)) 
Table 4 Disaster historical records in Sainthamaruthu Divisional Secretariate division southeastern coast of Sri Lanka

\begin{tabular}{|c|c|c|}
\hline $\begin{array}{l}\text { Disaster } \\
\text { type }\end{array}$ & $\begin{array}{l}\text { Disaster event (Year/ } \\
\text { Date) }\end{array}$ & Description about the disaster \\
\hline \multirow[t]{5}{*}{ Cyclone } & 1845 (No date) & No historical records found \\
\hline & 1891 (No date) & Called "mini cyclone." No other records available \\
\hline & 1907 March 9 & Called "major cyclone," between midnight and 7 a.m. in the morning \\
\hline & 1921 (No date) & Mini cyclone \\
\hline & 1978 November 23 & Major cyclone, many houses were partially damaged and severe loss of livestock were reported \\
\hline \multirow[t]{3}{*}{ Flood } & 1933 & Flooding due to rain over the four-month period. \\
\hline & 1957 December 25 & Major flood and severe damage to many infrastructures \\
\hline & $\begin{array}{l}2010 \text { (During December/ } \\
\text { January) }\end{array}$ & Minor flood due to heavy rain in the residential areas, major damage to paddy fields \\
\hline Tsunami & 2004 December 26 & $\begin{array}{l}\text { The worst disaster in the history, with } 768 \text { people died, } 722 \text { houses completely destroyed, more than } \\
2,500 \text { houses partially damaged }\end{array}$ \\
\hline \multirow[t]{3}{*}{ Other } & 1935 famine & Due to no rain for more than six months, all paddy fields were abandoned leading to large scale famine \\
\hline & 1917 epidemic & Later in 1940, 1970, 1980, and 2006 many different infectious diseases were reported \\
\hline & $\begin{array}{l}1992 \text { September } 1 \text { bomb } \\
\text { blast }\end{array}$ & A bomb blasted at the village market, which killed 21 people \\
\hline
\end{tabular}

Table 4 provides the disaster type, year/date, and a brief description of disasters over the past century period in Sainthamaruthu in the southeastern coast of Sri Lanka.

The trajectory for two disaster events shown in Fig. 4 can be repeated for all the past disaster events as shown in Fig. 5 (adapted from Béné et al. (2016) for disaster events in Sainthamaruthu in the southeastern coast of Sri Lanka), if the resilience status of a community after every shock $\left(e_{i}\right)$ is known relative to the previous disaster event $\left(e_{i+1}\right)$. According to Béné et al. (2016, p. 165), households sometimes do not completely recover from the shock when the next shock hits, which is characterized as "a constant state of incomplete recovery" from multi-shocks multistressors context as illustrated in Fig. 5, such as between $e_{8}$ and $e_{9}$. The same trajectory could be true for the community as a whole and for social resilience, although the resilience status among different households in a community may vary widely. For example, the complete functionality of community organizations may not have recovered due to consequent disaster events. This leads to a similar state of incomplete recovery of social resilience characteristics. Further, the sustainability of resilience recovery should be a concern in the post-disaster recovery process, which is more than simply rebuilding a resilient
Fig. 5 Resilience trajectory in a major multi-disaster context for Sainthamaruthu disaster events. $e_{1}-1845, e_{2}-1891, e_{3}-1907$, $e_{4}-1921, e_{7}-1978$ Cyclone events. $e_{5}-1933, e_{6}-1957, e_{9}-$ 2010 Flood events. $e_{8}-2004$

Tsunami event. Source Adapted from Béné et al. (2016)

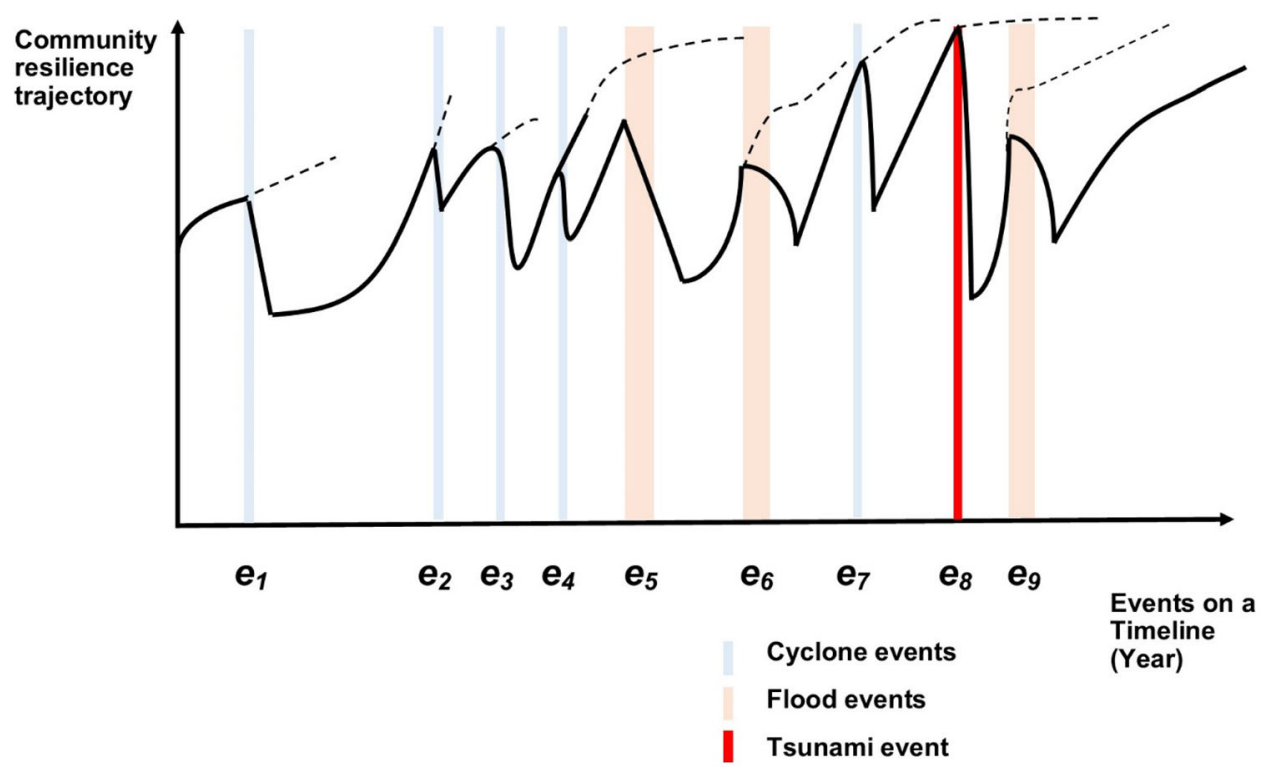


community to reduce future disaster risks, but facilitates sustainable development (Sou 2019).

\section{Conclusion and Recommendations for Future Research}

This article has critically reviewed social resilience definitions, properties, and pathways to address the existing multiple research gaps, including: (1) an alternative conceptualization of resilience definition using systems thinking; (2) the projection of resilience properties in a development and regeneration context; and (3) the development of the resilience trajectory in the multiple consecutive disaster timeline.

The systems thinking for conceptualizing social resilience can be further expanded to develop conceptual maps with multiple social resilience characteristics that can provide a basis for defining and framing social resilience broadly and to adapt it in a specific context. Further, the " $4 \mathrm{R}$ " properties (robustness, redundancy, resourcefulness, and rapidity) mostly considered in a single disaster context is expanded with " $6 \mathrm{R}$ " properties (risk-sensitivity and regenerative properties) in ex-ante/ex-post phases of two subsequent disaster events (Fig. 3). In this review, a social resilience causal pathway of a community to two subsequent disaster events (past and future) was also comprehended in a trajectory (Fig. 4). While most of the existing trajectories in the literature have considered a single disaster, the trajectory between two consecutive disaster events as shown in Fig. 4 is useful since the resilience to a past disaster influences the resilience status of a community to a future disaster. A resilience trajectory for multipledisaster events (Fig. 5) was also drawn with a historical example from the southeastern coast of Sri Lanka, which helps to advance the longitudinal research on community resilience to disasters in a historical timeline.

The review of existing definitions, properties, and trajectories highlighted the need for integrated conceptualization of social resilience in different phases of a disaster timeline and along the consecutive multiple disasters. The proposed additional or alternative conceptualization measures in definitions, properties, and trajectories will assist disaster management policymakers and practitioners to position social resilience within a holistic framework.

The following recommendations were also drawn by critically reviewing social resilience definitions, properties, and pathways in this study. First, review of social resilience definitions found that many definitions failed to consider the abilities of social mechanisms to cope with, withstand, and recover from disasters. There is a need to formulate a practical and operational definition of social resilience and to develop consistent frameworks to adequately measure social resilience in a disaster context (Cuthill et al. 2008; Henly-Shepard et al. 2015). Reaching a consensus on resilience definitions and concepts is often a challenge (Manyena 2006). However, an adaptive social resilience model such as the " $5 \mathrm{~S}$ " model developed by Saja et al. (2018) can serve as a foundational basis for holistic and integrated approach in disaster risk reduction and enables a comprehensive understanding of influences and interconnections between multiple levels of social systems. The dynamic relationships between different social dimensions need to be captured when conceptualizing social resilience, because these are often not considered due to complexity in deconstructing the dynamic resilience features (Saja et al. 2019).

Second, resilience literature in a disaster context is dominated by cross-sectional studies, while the changes in social resilience in different phases of a disaster and the resilience pathway to an emerging disaster have not been investigated in detail in the existent literature. Longitudinal studies should be conducted to understand how the relationships of social resilience evolve in pre- and post-disaster phases, which will offer an understanding of social resilience trajectories and disaster event-based changes in resilience status.

Third, more studies are needed to benchmark key resilience properties such as the " $6 \mathrm{R}$ " properties discussed in this article. With increasing dominance of the resilience debate in disaster and development policy making and practice, new research needs to align its direction with the sustainable development goals (integrating risk-sensitivity components), which may offer an insight to measuring the thresholds of resilience properties.

Acknowledgments We acknowledge the University Grants Commission of Sri Lanka (UGCSL) and Queensland University of Technology (QUT), Australia for providing research scholarship to the first author for undertaking this study.

Open Access This article is licensed under a Creative Commons Attribution 4.0 International License, which permits use, sharing, adaptation, distribution and reproduction in any medium or format, as long as you give appropriate credit to the original author(s) and the source, provide a link to the Creative Commons licence, and indicate if changes were made. The images or other third party material in this article are included in the article's Creative Commons licence, unless indicated otherwise in a credit line to the material. If material is not included in the article's Creative Commons licence and your intended use is not permitted by statutory regulation or exceeds the permitted use, you will need to obtain permission directly from the copyright holder. To view a copy of this licence, visit http://creativecommons. org/licenses/by/4.0/.

\section{References}

Adger, W.N. 2000. Social and ecological resilience: Are they related?. Progress in Human Geography 24(3): 347-364. 
Ainuddin, S., and J.K. Routray. 2012. Earthquake hazards and community resilience in Baluchistan. Natural Hazards 63(2): 909-937.

Aldunce, P., R. Beilin, M. Howden, and J. Handmer. 2015. Resilience for disaster risk management in a changing climate: Practitioners' frames and practices. Global Environmental Change 30: $1-11$.

Alexander, D.E. 2013. Resilience and disaster risk reduction: An etymological journey. Natural Hazards and Earth System Sciences 13(11): 2707-2716.

Bahadur, A., T. Tanner, D. King, A. Kirbyshire, and H. Morsi. 2015. Resilience scan October-December 2015: A review of literature, debates and social media activity on resilience. London: Overseas Development Institute.

Bahadur, A.V., K. Peters, E. Wilkinson, F. Pichon, K. Gray, and T. Tanner. 2015. The 3As: Tracking resilience across BRACED. London: Overseas Development Institute (ODI). https://cdn.odi. org/media/documents/9812.pdf. Accessed 20 Aug 2018.

Béné, C., R.M. Al-Hassan, O. Amarasinghe, P. Fong, J. Ocran, E. Onumah, R. Ratuniata, and T. Van Tuyen et al. 2016. Is resilience socially constructed? Empirical evidence from Fiji, Ghana, Sri Lanka, and Vietnam. Global Environmental Change 38: $153-170$

Béné, C., T. Frankenberger, and S. Nelson. 2015. Design, monitoring and evaluation of resilience interventions: Conceptual and empirical considerations. IDS Working Paper No. 459. Brighton, UK: Institue of Development Studies.

Birnbaum, M.L., E.K. Daily, A.P. O'Rourke, and A. Loretti. 2016. Research and evaluations of the health aspects of disasters, Part IX: Risk-reduction framework. Prehospital and Disaster Medicine 31(3): 309-325.

Boin, A., L.K. Comfort, and C.C. Demchak. 2010. The rise of resilience. In Designing resilience: Preparing for extreme events, ed. L.K. Comfort, A. Boin, and C.C. Demchak, 1-12. Pittsburgh, PA: University of Pittsburgh Press.

Boon, H.J., A. Cottrell, D. King, R.B. Stevenson, and J. Millar. 2012. Bronfenbrenner's bioecological theory for modelling community resilience to natural disasters. Natural Hazards 60(2): 381-408.

Boon, H.J., A. Cottrell, and D. King. 2016. Disasters and social resilience: A bioecological approach. London: Routledge.

Bruneau, M., S.E. Chang, R.T. Eguchi, G.C. Lee, T.D. O'Rourke, A.M. Reinhorn, M. Shinozuka, and K. Tierney et al. 2003. A framework to quantitatively assess and enhance the seismic resilience of communities. Earthquake Spectra 19(4): 733-752.

Buckle, P. 2006. Assessing social resilience. In Disaster resilience: An integrated approach, ed. D. Paton, and D.M. Johnston, 88-103. Springfield, IL: Charles C Thomas Publisher.

Burton, C.G. 2015. A validation of metrics for community resilience to natural hazards and disasters using the recovery from Hurricane Katrina as a case study. Annals of the Association of American Geographers 105(1): 67-86.

Chambers, K.F., A.C. Baker, S.K. McKay, and H. Morgan. 2019. Retrospective sustainability and resilience: Complementary concepts for managing systems. Vicksburg, MS: Engineer Research and Development Center (ERDC).

Chandra, A., J. Acosta, L.S. Meredith, K. Sanches, S. Stern, L. Uscher-Pines, M. Williams, and D. Yeung. 2010. Understanding community resilience in the context of national health security: A literature review. Santa Monica, CA: RAND Corporation.

Constas, M., T. Frankenberger, J. Hoddinott, N. Mock, D. Romano, C. Béné, and D. Maxwell. 2014. A common analytical model for resilience measurement: Causal framework and methodological options. In Food Security Information Network Resilience Measurement Technical Working Group. https://www.fsnnet work.org/resource/common-analytical-model-resilience- measurement-causal-framework-and-methodological-options. Accessed 10 Sept 2018.

Coslet, C., S. Goodbody, and C. Guccione. 2017. Special report of FAO/WFP crop and food security assessment mission to Sri Lanka. Rome: FAO/WFP.

Cox, R.S., and M. Hamlen. 2015. Community disaster resilience and the rural resilience index. American Behavioral Scientist 59(2): 220-237.

Cuthill, M., H. Ross, K. Maclean, K. Owens, B. Witt, and C. King. 2008. Reporting social outcomes of development: An analysis of diverse approaches. International Journal of Interdisciplinary Social Sciences 3(6): 145-157.

Cutter, S.L. 2016. The landscape of disaster resilience indicators in the USA. Natural Hazards 80(2): 741-758.

Day, S. 2015. Rebuilding post-disaster community resilience: A complex adaptive systems approach. Flagstaff, AZ: Northern Arizona University.

De Bruijne, M., A. Boin, and M. Van Eeten. 2010. Resilience: Exploring the concept and its meanings. In Designing resilience: Preparing for extreme events, ed. L.K. Comfort, A. Boin, and C.C. Demchak, 13-32. Pittsburgh, PA: University of Pittsburgh Press.

Engle, N.L. 2011. Adaptive capacity and its assessment. Global Environmental Change 21(2): 647-656.

ESCAP (United Nations Economic and Social Commission for Asia and the Pacific). 2015. Risk-sensitive development in Asia and the Pacific. Bangkok: ESCAP Committee on Disaster Risk Reduction, United Nations.

Folke, C., S. Carpenter, B. Walker, M. Scheffer, T. Chapin, and J. Rockström. 2010. Resilience thinking: Integrating resilience, adaptability and transformability. Ecology and Society 15(4): 20.

Frankenberger, T., M. Langworthy, T. Spangler, S. Nelson, J. Campbell, and J. Njoka. 2012. Enhancing resilience to food security shocks. https://www.fsnnetwork.org/sites/default/files/ discussion_paper_usaid_dfid_wb_nov._8_2012.pdf. Accessed 10 Sept 2021.

Henly-Shepard, S., C. Anderson, K. Burnett, L.J. Cox, J.N. Kittinger, and M. Ka'aumoana. 2015. Quantifying household social resilience: A place-based approach in a rapidly transforming community. Natural Hazards 75(1): 343-363.

Jameel, M.I.M., and A.H.M. Musthaffa. 2009. Disaster history of Sainthamaruthu village. In History of sainthamaruthu, sainthamaruthu: community welfare and disaster management council, ed. M.I.M. Jameel, and A.H.M. Musthaffa, 449. SainthamaruthuMaligaikadu, Sri Lanka: Grand Mosque.

Keck, M., and P. Sakdapolrak. 2013. What is social resilience? Lessons learned and ways forward. Erdkunde 67(1): 5-19.

Khalili, S., M. Harre, and P. Morley. 2015. A temporal framework of social resilience indicators of communities to flood, case studies: Wagga wagga and Kempsey, NSW, Australia. International Journal of Disaster Risk Reduction 13: 248-254.

Kimhi, S., and M. Shamai. 2004. Community resilience and the impact of stress: Adult response to Israel's withdrawal from Lebanon. Journal of Community Psychology 32(4): 439-451.

Klein, R.J.T., R.J. Nicholls, and F. Thomalla. 2003. Resilience to natural hazards: How useful is this concept?. Global Environmental Change Part B: Environmental Hazards 5(1-2): 35-45.

Kulig, J., and A.P. Botey. 2016. Facing a wildfire: What did we learn about individual and community resilience?. Natural Hazards 82(3): 1919-1929.

Kwok, A.H., E.E.H. Doyle, J. Becker, D. Johnston, and D. Paton. 2016. What is "social resilience"? Perspectives of disaster researchers, emergency management practitioners, and policymakers in New Zealand. International Journal of Disaster Risk Reduction 19: 197-211. 
Lorenz, D.F. 2013. The diversity of resilience: Contributions from a social science perspective. Natural Hazards 67(1): 7-24.

Maclean, K., M. Cuthill, and H. Ross. 2014. Six attributes of social resilience. Journal of Environmental Planning and Management 57(1): 144-156.

Maguire, B., and P. Hagan. 2007. Disasters and communities: Understanding social resilience. Australian Journal of Emergency Management 22(2): 16-20.

Manyena, S.B. 2006. The concept of resilience revisited. Disasters 30(4): 434-450.

Manyena, B. 2016. After Sendai: Is Africa bouncing back or bouncing forward from disasters?. International Journal of Disaster Risk Science 7(1): 41-53.

Masnavi, M.R., F. Gharai, and M. Hajibandeh. 2018. Exploring urban resilience thinking for its application in urban planning: A review of literature. International Journal of Environmental Science and Technology 16(2): 567-582.

Matyas, D., and M. Pelling. 2015. Positioning resilience for 2015: The role of resistance, incremental adjustment and transformation in disaster risk management policy. Disasters 39(S1): s1-s18.

Mayunga, J.S. 2007. Understanding and applying the concept of community disaster resilience: A capital-based approach. A draft working paper prepared for the Summer Academy for Social Vulnerability and Resilience Building, 22-28 July 2007, Munich, Germany.

McMillen, H., L. Campbell, E. Svendsen, and R. Reynolds. 2016. Recognizing stewardship practices as indicators of social resilience: In living memorials and in a community garden. Sustainability 8(8): 775.

Nelson, D.R., W.N. Adger, and K. Brown. 2007. Adaptation to environmental change: Contributions of a resilience framework. Annual Review of Environment and Resources 32: 395-419.

Norris, F.H., S.P. Stevens, B. Pfefferbaum, K.F. Wyche, and R.L. Pfefferbaum. 2008. Community resilience as a metaphor, theory, set of capacities, and strategy for disaster readiness. American Journal of Community Psychology 41(1-2): 127-150.

Oliver, A., I. Thomas, and M.M. Thompson. 2013. Resilient and regenerative design in New Orleans: The case of the Make It Right project. Surveys and Perspectives Integrating Environment and Society 6(1). http://journals.openedition.org/sapiens/1610.

Parsons, M., S. Glavac, P. Hastings, G. Marshall, J. McGregor, J. McNeill, P. Morley, I. Reeve, and R. Stayner. 2016. Top-down assessment of disaster resilience: A conceptual framework using coping and adaptive capacities. International Journal of Disaster Risk Reduction 19: 1-11.

Perera, A. 2012. Between drought and floods - A year of extremes in Sri Lanka. Inter Press Service News Agency, 30 December 2012. http://www.ipsnews.net/2012/12/between-drought-and-floods-ayear-of-extremes-in-sri-lanka/. Accessed 25 Sept 2019.

Pfefferbaum, R.L., B. Pfefferbaum, R.L. Van Horn, R.W. Klomp, F.H. Norris, and D.B. Reissman. 2013. The communities advancing resilience toolkit (CART): An intervention to build community resilience to disasters. Journal of Public Health Management and Practice 19(3): 250-258.

Quinlan, A.E., M. Berbés-Blázquez, L.J. Haider, and G.D. Peterson. 2015. Measuring and assessing resilience: Broadening understanding through multiple disciplinary perspectives. Journal of Applied Ecology 53(3): 677-687.
Rockström, J. 2003. Resilience building and water demand management for drought mitigation. Physics and Chemistry of the Earth, Parts A/B/C 28(20): 869-877.

Rose, A., and E. Krausmann. 2013. An economic framework for the development of a resilience index for business recovery. International Journal of Disaster Risk Reduction 5: 73-83.

Saja, A.M.A., M. Teo, A. Goonetilleke, and A.M. Ziyath. 2018. An inclusive and adaptive framework for measuring social resilience to disasters. International Journal of Disaster Risk Reduction 28: $862-873$.

Saja, A.M.A., A. Goonetilleke, M. Teo, and A.M. Ziyath. 2019. A critical review of social resilience assessment frameworks in disaster management. International Journal of Disaster Risk Reduction 35: 101096.

Saja, A.M.A., M. Teo, A. Goonetilleke, and A.M. Ziyath. 2021. Assessing social resilience in disaster management. International Journal of Disaster Risk Reduction 52: 101957.

Serfilippi, E., and G. Ramnath. 2018. Resilience measurement and conceptual frameworks: A review of the literature. Annals of Public and Cooperative Economics 89(4): 645-664.

Sharifi, A. 2020. Urban resilience assessment: Mapping knowledge structure and trends. Sustainability 12(15): 5918.

Shaw, D., J. Scully, and T. Hart. 2014. The paradox of social resilience: How cognitive strategies and coping mechanisms attenuate and accentuate resilience. Global Environmental Change 25: 194-203.

Sherrieb, K., F.H. Norris, and S. Galea. 2010. Measuring capacities for community resilience. Social Indicators Research 99(2): $227-247$

Sou, G. 2019. Sustainable resilience? Disaster recovery and the marginalization of sociocultural needs and concerns. Progress in Development Studies 19(2): 144-159.

Timmerman, P. 1981. Vulnerability, resilience and collapse of society: A review of models and possible climatic applications. Toronto: Institute for Environmental Studies, University of Toronto.

UNDRR (United Nations Office for Disaster Risk Reduction). 2019. Global assessment report on disaster risk reduction. Geneva: UNDRR.

UNISDR (United Nations International Strategy for Disaster Reduction). 2009. 2009 UNISDR terminology on disaster risk reduction. Geneva: UNISDR.

UNISDR (United Nations International Strategy for Disaster Reduction). 2015. Proposed updated terminology on disaster risk reduction: A technical review. Geneva: UNISDR.

UNISDR (United Nations International Strategy for Disaster Reduction). 2015. Sendai framework for disaster risk reduction 2015-2030. Geneva: UNISDR.

Xue, X., L. Wang, and R.J. Yang. 2018. Exploring the science of resilience: Critical review and bibliometric analysis. Natural Hazards 90(1): 477-510.

Zhou, H., J. Wang, J. Wan, and H. Jia. 2010. Resilience to natural hazards: A geographic perspective. Natural Hazards 53(1): 21-41. 